\title{
Development and Validation of a Single-Item Screener for Self- Reporting Sexual Problems in U.S. Adults
}

\author{
Kathryn E. Flynn, PhD ${ }^{7}$, Stacy Tessler Lindau, MD 2,3 , Li Lin, MS ${ }^{4}$, Jennifer Barkky Reese, PhD ${ }^{5}$, \\ Diana D. Jeffery, $P h D^{6}$, Jeanne Carter, $P h D^{7}$, Shirley R. Baron, $P h D^{8}$, Emily Abramsohn, MPH ${ }^{2}$, \\ and Kevin P. Weinfurt, $P h D^{4,9}$
}

${ }^{1}$ Center for Patient Care and Outcomes Research, Department of Medicine, Medical College of Wisconsin, Milwaukee, WI, USA; ${ }^{2}$ Department of Obstetrics/Gynecology, University of Chicago, Chicago, IL, USA; ${ }^{3}$ Department of Medicine-Geriatrics, Comprehensive Cancer Center, University of Chicago, Chicago, IL, USA; ${ }^{4}$ Duke Clinical Research Institute, Duke University School of Medicine, Durham, NC, USA; ${ }^{5}$ Cancer Prevention and Control Program, Fox Chase Cancer Center, Philadelphia, PA, USA; 'DDefense Health Agency, Department of Defense, Falls Church, VA, USA; ${ }^{7}$ Departments of Surgery and Psychiatry, Memorial Sloan Kettering Cancer Center, New York, NY, USA; ${ }^{8}$ Department of Psychiatry and Behavioral Sciences, Feinberg School of Medicine, Northwestern University, Chicago, IL, USA; ${ }^{9}$ Department of Psychiatry and Behavioral Sciences, Duke University School of Medicine, Durham, NC, USA.

BACKGROUND: Brief self-assessment of sexual problems in a clinical context has the potential to improve care for patients through the ability to track trends in sexual problems over time and facilitate patient-provider communication about this important topic. However, instruments designed for research are typically too long to be practical in clinical practice.

OBJECTIVE: To develop and validate a single-item selfreport clinical screener that would capture common sexual problems and concerns for men and women.

DESIGN: We created three candidate screener items, refined them through cognitive interviews, and administered them to a large sample. We compared the prevalence of responses to each item and explored the discrepancies between items. We evaluated the construct validity of the items by comparing them to scores on the PatientReported Outcomes Measurement Information System® Sexual Function and Satisfaction (PROMIS® SexFS) measure.

PARTICIPANTS: Local patients participated in two rounds of cognitive interviews $(n=7$ and $n=11)$. A probability-based random sample of U.S. adults comprised the item-testing sample ( $\mathrm{n}=3517)$.

MAIN MEASURES: The items were as follows: 1) a yes/no item on any sexual problems or concerns ("general screener"), 2) a yes/no item on problems experienced for 3 months or more during the past 12 months, with a list of examples ("long list screener"), and 3) an item identical to the long list screener except that examples appeared individually as response options and respondents could check all that applied ("checklist screener").

KEY RESULTS: All of the screeners tested showed evidence for basic validity and had minimal missing data. Percentages of women and men endorsing the screeners were $10 \%$ and $15 \%$ (general); $20 \%$ and $17 \%$ (long list);

Electronic supplementary material The online version of this article (doi:10.1007/s11606-015-3333-3) contains supplementary material, which is available to authorized users.

Received September 8, 2014

Revised January 12, 2015

Accepted March 30, 2015

Published online April 18, 2015 and $38 \%$ and $30 \%$ (checklist), respectively. Participants who endorsed the screeners had lower function compared to those who did not endorse them.

CONCLUSIONS: We recommend the checklist screener for its specificity and ability to identify specific problems associated with decreased sexual function.

J Gen Intern Med 30(10): 1468-75

DOI: $10.1007 / \mathrm{s} 11606-015-3333-3$

(C) Society of General Internal Medicine 2015

\section{INTRODUCTION}

The prevalence of sexual problems in adults is high, ranging from 30-50 \%. In the U.S. National Health and Social Life Survey (in-person interviews in 1992), $43 \%$ of women and $31 \%$ of men aged $18-59$ who had been sexually active in the past year self-reported at least one sexual problem. ${ }^{1}$ The U.S. National Social Life, Health, and Aging Project (in-person interviews in 2005-06) found that over half of sexually active adults aged 57-85 reported a sexual problem lasting several months or more. ${ }^{2}$ Despite the high prevalence of problems, assessing sexual function during clinic visits is not commonplace. Limited patient-provider communication about sexual matters has been documented in primary care, ${ }^{3,4}$ ob/gyn, ${ }^{5}$ cardiology, ${ }^{6}$ and oncology. ${ }^{7,8}$ Patients can be reluctant to initiate discussions with their providers about sexual function, preferring that providers broach the topic. ${ }^{7,9}$ Providers can also be reluctant to raise the subject, ${ }^{10}$ especially if they feel they lack the knowledge or skills needed to address this issue, ${ }^{11}$ yet there is some evidence that a pre-visit questionnaire can promote patient-provider discussions of sexual dysfunction. ${ }^{12}$ Given the availability of treatments and options for referrals for sexual problems, the routine assessment of sexual concerns might reduce barriers to discussing this issue while also providing a means to assess longitudinal changes in an important area of health. Therefore, the availability of easily administered and interpreted tools to assess sexual concerns could improve clinical care and standardize data collection efforts for research. 
Multiple validated instruments are available for selfassessment of sexual function, but validated instruments designed for research (e.g., the International Index of Erectile Function $^{13}$, the Female Sexual Function Index ${ }^{14}$, and the Patient-Reported Outcomes Measurement Information System ${ }^{\circledR}$ Sexual Function and Satisfaction Sexual Function and Satisfaction [PROMIS ${ }^{\circledR}$ SexFS] measure ${ }^{19}$ ) are typically too long to be practical in general clinical practice settings. Brief self-assessment of sexual problems in a clinical context has the potential to improve clinical care by tracking trends in sexual problems over time and facilitating patient-provider communication about sexual function. Very brief assessments may also reduce missing data, which is desirable in both the clinical and research context. Therefore, our objective was to develop and validate a single-item clinical screener that would capture common sexual problems and concerns for men and women. This work was conducted in conjunction with the development of version 2.0 of the PROMIS SexFS measure and informed by members of the Scientific Network on Female Sexual Health and Cancer (http://cancersexnetwork.org), an international interdisciplinary network of clinicians and researchers.

\section{METHODS}

We created three single-item screeners, which were informed by the self-report items currently used by several members of the Scientific Network on Female Sexual Health and Cancer in clinic intake forms. This included items used in oncology, gynecology, and sexual medicine clinics. We solicited and incorporated additional feedback on the screeners from other members of this group as well as from members of the PROMIS Sexual Function domain group.

We tested and refined the screeners in conjunction with qualitative and psychometric testing for version 2.0 of the PROMIS SexFS. Qualitative testing included two rounds of cognitive interviews ( $\mathrm{n}=7$ and $\mathrm{n}=11$ ) with participants recruited through physician letters and the clinical trials website of the Duke University Health System. Interviews were conducted in person by an interviewer of the same sex as the participant. ${ }^{15}$ The specific cognitive interview methodology used is described in detail elsewhere. ${ }^{16}$ Participants in psychometric testing were members of the GfK KnowledgePanel ${ }^{\circledR}$, which comprises a probability-based sample of U.S. mailing addresses weighted to provide a valid representation of the U.S. population. For those selected who do not have Internet access, GfK supplies a computer and Internet service. ${ }^{17}$ Participants completed an online self-report survey covering basic sociodemographic and health concepts, the PROMIS SexFS, and the clinical screeners. All screeners were asked of all participants. Additional details about study design are provided in the appendix. The institutional review board of the Duke University Health System approved this study, and participants provided informed consent.

\section{Clinical Screeners}

The three screeners, administered in order during item testing, were as follows: 1) a yes/no item with no recall period asking about any sexual problems or concerns ("general screener"), 2) a yes/no item asking whether, in the past 12 months, the person had experienced any problems for 3 months or more, with a detailed list of example problems ("long list screener"), and 3) an item that was identical to the long list except that it moved the examples of problems from the item stem (i.e., the question itself) to the response options and included the instruction to "check all that apply" ("checklist screener"). Respondents who chose "some other problem or concern" in the checklist screener were asked to specify the problem (open-ended response).

\section{PROMIS SexFS}

To provide evidence for the validity of the single-item screeners, we related responses on the screeners to robust sexual function scores as measured by the PROMIS SexFS, a comprehensive measure designed for research. ${ }^{18-20}$ The PROMIS SexFS version 2.0 includes 17 domains. For individuals who had been sexually active in the past 30 days, we used the domains most closely corresponding to the response options in the checklist screener for comparisons (shown in Table 4). For each PROMIS SexFS domain, a higher score represents more of that domain; for example, a higher Erectile Function score reflects better erectile function, and a higher Vaginal Discomfort score reflects greater vaginal discomfort. PROMIS SexFS domain scores are expressed on a T-score metric in which a score of 50 corresponds to the U.S. general population average for sexually active adults and has a standard deviation of $10 .{ }^{21}$ Participants who had not been sexually active with a partner during the past 30 days were asked to provide the reasons for lack of activity. Again, we used the response options related to sexual function and satisfaction that most closely corresponded to the content in the checklist screener.

Our analyses also utilized items from the PROMIS SexFS Bother Regarding Sexual Function domain that asked how bothered the person was by their sexual function in key domains. These items were reported on a five-point scale ranging from "not at all" to "very much."

\section{Analytic Approach}

We used means and standard errors (SEs) to summarize continuous and ordinal variables and the frequencies and percentages for discrete variables with complex survey sample design weighting applied. Assuming that the problems endorsed on the checklist screener represented the true set of problems that people had experienced, we explored the discrepancies between the responses to the long list and checklist screeners in three ways. We hypothesized that discrepancies might be explained by 1) the number of problems someone had, where people who 
Table 1 Weighted Sample Characteristics* $(n=3515)$

\begin{tabular}{|c|c|c|c|}
\hline Characteristic & Total $(n=3515)$ & Male $(n=1757)$ & Female $(n=1758)$ \\
\hline \multicolumn{4}{|l|}{ Age group } \\
\hline $18-29$ & $750(21.3 \%)$ & $398(22.7 \%)$ & $352(20.0 \%)$ \\
\hline $30-44$ & $882(25.1 \%)$ & $448(25.5 \%)$ & $434(24.7 \%)$ \\
\hline $45-59$ & $982(27.9 \%)$ & $487(27.7 \%)$ & $495(28.2 \%)$ \\
\hline $60+$ & $901(25.6 \%)$ & $424(24.1 \%)$ & $477(27.1 \%)$ \\
\hline \multicolumn{4}{|l|}{ Race } \\
\hline Black or African American & $433(12.3 \%)$ & $199(11.3 \%)$ & $234(13.3 \%)$ \\
\hline American Indian/Alaska Native & $41(1.2 \%)$ & $14(0.8 \%)$ & $27(1.5 \%)$ \\
\hline Asian & $138(3.9 \%)$ & $80(4.6 \%)$ & $58(3.3 \%)$ \\
\hline Native Hawaiian/Other Pacific Islander & $13(0.4 \%)$ & $6(0.3 \%)$ & $8(0.4 \%)$ \\
\hline White & $2778(79.0 \%)$ & $1406(80.0 \%)$ & $1371(78.0 \%)$ \\
\hline Multiple races or other & $112(3.2 \%)$ & $52(3.0 \%)$ & $60(3.4 \%)$ \\
\hline Hispanic or Latino ethnicity & $459(13.1 \%)$ & $252(14.3 \%)$ & $207(11.8 \%)$ \\
\hline \multicolumn{4}{|l|}{ Sexual identity } \\
\hline Heterosexual or straight & $3314(94.3 \%)$ & $1662(94.5 \%)$ & $1652(94.0 \%)$ \\
\hline Gay & $67(1.9 \%)$ & $61(3.5 \%)$ & $6(0.3 \%)$ \\
\hline Lesbian & $23(0.6 \%)$ & - & $23(1.3 \%)$ \\
\hline Bisexual & $74(2.1 \%)$ & $19(1.1 \%)$ & $55(3.1 \%)$ \\
\hline Other & $37(1.1 \%)$ & $16(0.8 \%)$ & $21(1.2 \%)$ \\
\hline \multicolumn{4}{|l|}{ Educational attainment } \\
\hline Less than high school & $399(11.3 \%)$ & $212(10.5 \%)$ & $186(10.5 \%)$ \\
\hline High school graduate/GED & $1056(30.0 \%)$ & $528(30.0 \%)$ & $529(30.1 \%)$ \\
\hline Some college & $749(21.3 \%)$ & $383(21.8 \%)$ & $366(20.8 \%)$ \\
\hline College degree & $897(25.5 \%)$ & $417(20.7 \%)$ & $480(32.0 \%)$ \\
\hline Advanced degree (MA, PhD, MD) & $415(11.8 \%)$ & $218(10.8 \%)$ & $197(13.1 \%)$ \\
\hline \multicolumn{4}{|l|}{ Relationship status } \\
\hline Married, civil union, or domestic partnership & $1863(53.0 \%)$ & $991(56.4 \%)$ & $872(49.6 \%)$ \\
\hline Living with a partner & $328(9.3 \%)$ & $146(8.3 \%)$ & $182(10.4 \%)$ \\
\hline In a relationship but not living together & $262(7.4 \%)$ & $118(6.7 \%)$ & $144(8.2 \%)$ \\
\hline Dating & $177(5.0 \%)$ & $88(5.0 \%)$ & $89(5.1 \%)$ \\
\hline Single & $760(21.6 \%)$ & $380(21.6 \%)$ & $380(21.6 \%)$ \\
\hline Other & $116(3.3 \%)$ & $34(1.9 \%)$ & $81(4.6 \%)$ \\
\hline \multicolumn{4}{|l|}{ Employment status } \\
\hline Working (employee or self-employed) & $1946(55.3 \%)$ & $1088(53.9 \%)$ & $857(57.2 \%)$ \\
\hline On temporary layoff or looking for work & $410(11.6 \%)$ & $193(9.5 \%)$ & $215(14.3 \%)$ \\
\hline Retired & $636(18.0 \%)$ & $294(16.7 \%)$ & $342(19.5 \%)$ \\
\hline Disabled & $251(7.1 \%)$ & $129(7.4 \%)$ & $122(6.9 \%)$ \\
\hline Other & $274(7.8 \%)$ & $53(2.6 \%)$ & $221(12.6 \%)$ \\
\hline \multicolumn{4}{|l|}{ Household income group (\$) } \\
\hline$<25,000$ & $660(18.7 \%)$ & $296(14.7 \%)$ & $365(24.3 \%)$ \\
\hline $25,001-50,000$ & $827(23.5 \%)$ & $399(19.8 \%)$ & $426(28.4 \%)$ \\
\hline $50,001-75,000$ & $674(19.1 \%)$ & $354(17.5 \%)$ & $319(21.2 \%)$ \\
\hline $75,001-100,000$ & $525(14.9 \%)$ & $272(13.4 \%)$ & $283(18.8 \%)$ \\
\hline$>100,001$ & $831(23.6 \%)$ & $466(23.1 \%)$ & $365(24.3 \%)$ \\
\hline \multicolumn{4}{|l|}{ Health conditions } \\
\hline Hypertension & $901(25.6 \%)$ & $459(26.1 \%)$ & $442(25.1 \%)$ \\
\hline Arthritis or rheumatism & $688(19.6 \%)$ & $259(14.7 \%)$ & $429(24.4 \%)$ \\
\hline Depression & $591(16.8 \%)$ & $216(12.3 \%)$ & $375(21.3 \%)$ \\
\hline Anxiety & $492(14.0 \%)$ & $192(10.9 \%)$ & $300(17.1 \%)$ \\
\hline Migraines or severe headaches & $434(12.4 \%)$ & $133(7.6 \%)$ & $301(17.1 \%)$ \\
\hline Diabetes (type I or Type II) & $406(11.5 \%)$ & $188(10.7 \%)$ & $218(12.4 \%)$ \\
\hline Asthma & $323(9.2 \%)$ & $144(8.2 \%)$ & $179(10.2 \%)$ \\
\hline Heart disease & $302(8.6 \%)$ & $178(10.1 \%)$ & $124(7.1 \%)$ \\
\hline Cancer (other than non-melanoma skin cancer) & $198(5.6 \%)$ & $86(4.9 \%)$ & $113(6.4 \%)$ \\
\hline Coronary artery disease (CAD) & $91(2.6 \%)$ & $61(3.5 \%)$ & $30(1.7 \%)$ \\
\hline \multicolumn{4}{|l|}{ General self-rated health } \\
\hline Excellent & $603(17.2 \%)$ & $319(18.1 \%)$ & $285(16.2 \%)$ \\
\hline Very good & $1272(36.2 \%)$ & $650(37.0 \%)$ & $622(35.4 \%)$ \\
\hline Good & $1023(29.1 \%)$ & $492(28.0 \%)$ & $531(30.2 \%)$ \\
\hline Fair & $436(12.4 \%)$ & $202(11.5 \%)$ & $234(13.3 \%)$ \\
\hline Poor & $95(2.7 \%)$ & $41(2.3 \%)$ & $54(3.1 \%)$ \\
\hline
\end{tabular}

* Not all fields add to 100 due to rounding and weighting

said "yes" to the long list screener would indicate having more problems, 2) the specific problems that people had, where people who said "yes" to the long list screener would indicate having a problem other than "no interest," and/or 3) the level of bother associated with any problems, where people who said "yes" to the long list would be more bothered by their problem.
We evaluated the construct validity of the checklist screener in two ways. First, among sexually active participants, we estimated the difference in mean and $95 \%$ confidence interval for each domain, hypothesizing that endorsing a problem on the checklist screener would be associated with worse functioning on the corresponding PROMIS SexFS domain. Since 10 points is equivalent to 1 standard deviation in score, by 
adapting standard criteria used for evaluating for effect sizes, ${ }^{22}$ we considered two points a small difference, five points a medium difference, and eight points a large difference. Second, among non-sexually active participants, we tested the difference in the percentage of men and women who endorsed each reason using chi-square, hypothesizing that endorsing a problem on the checklist screener would be associated with a higher likelihood of choosing the corresponding reason for not having sexual activity with a partner in the past month.

We used SAS software version 9.2 (SAS Institute, Cary, NC) and a two-tailed significance level of $\alpha=0.05$ for all assessments. All statistics were adjusted for the sample design.

\section{RESULTS}

Table 1 shows the sample characteristics, weighted to represent the U.S. population. Table 2 shows the responses to the three single-item screeners as well as the number (count) of sexual problems or concerns that men and women endorsed in the checklist screener. Lack of interest (27\%) was the most prevalent concern for women; difficulty with erection (16\%) was the most prevalent concern for men. About $5 \%$ of men and women wrote in an "other" response, some of which could be recoded into existing categories. Most of the responses that were not recoded related to partner issues (e.g., lack of partner, partner's health, feeling unattractive, or lack of attraction to partner).
Missing data were minimal for all three screeners, $2-3 \%$ for women and $4-5 \%$ for men. There were large differences in the prevalence of sexual problems or concerns among the screeners. While $15 \%$ of men and $10 \%$ of women endorsed the general screener, $17 \%$ of men and $20 \%$ of women endorsed the long list screener, and $30 \%$ of men and $38 \%$ of women endorsed at least one problem on the checklist screener. Below we describe inconsistencies in responses; additional analyses are presented in the appendix.

\section{Explaining Inconsistencies in Responses}

First, there were differences in the number of problems people reported. Women and men who answered "yes" to the long list screener (vs. "no") endorsed a greater number of problems on the checklist screener, with a mean 2.5 problems compared to 1.3 for women and 1.8 problems compared to 1.2 for men, both $P<0.0001$.

Second, there were differences in the specific problems that were endorsed on the checklist screener. Women who answered "yes" to the long list (vs. "no") were more likely to indicate problems with lubrication ( $40 \%$ vs. $12 \%)$, pain ( $37 \%$ vs. $11 \%$ ), orgasm ( $36 \%$ vs. $11 \%$ ), sexual enjoyment ( $38 \%$ vs. $7 \%$ ), or anxiety ( $15 \%$ vs. $6 \%$ ). This was not the case for "no interest," which was endorsed similarly by women answering either "yes" or "no" on the long list screener ( $72 \%$ vs. $69 \%$ ). Men who answered "yes" to the long list (vs. "no") were more likely to indicate problems with erectile function ( $71 \%$ vs. $30 \%$ ), orgasm ( $23 \%$ vs. $12 \%$ ), or anxiety

Table 2 Prevalence of Sexual Problems for Men and Women Based on Single-Item Screeners (n=3515)

\begin{tabular}{|c|c|c|c|}
\hline Screener version & Total $(n=3515)$ & Male (n=1757) & Female $(n=1758)$ \\
\hline \multicolumn{4}{|l|}{ General screener } \\
\hline \multicolumn{4}{|c|}{ Do you have any sexual problems or concerns? } \\
\hline No & $2979(84.7 \%)$ & $1425(81.1 \%)$ & $1553(88.4 \%)$ \\
\hline Yes & $442(12.6 \%)$ & $265(15.1 \%)$ & $177(10.1 \%)$ \\
\hline Missing & $94(2.7 \%)$ & $67(3.8 \%)$ & $27(1.5 \%)$ \\
\hline \multicolumn{4}{|c|}{ Long list screener } \\
\hline \multicolumn{4}{|c|}{$\begin{array}{l}\text { In the past } 12 \text { months, has there ever been a period of } 3 \text { months or more when you experienced any sexual problems or concerns, such as, you had no } \\
\text { interest in sex, your vagina felt too dry (women), you had erection difficulties (men), you had pain during or after sex, you had difficulty having an } \\
\text { orgasm, you felt anxious about having sex, or you did not enjoy sex? }\end{array}$} \\
\hline No & $2740(78.0 \%)$ & $1383(78.7 \%)$ & $1357(77.2 \%)$ \\
\hline Yes & $650(18.5 \%)$ & $300(17.1 \%)$ & $349(19.9 \%)$ \\
\hline Missing & $125(3.6 \%)$ & $75(4.3 \%)$ & $51(2.9 \%)$ \\
\hline \multicolumn{4}{|l|}{ Checklist screener } \\
\hline In the past 12 months, has there ever be & nonths or more $\mathrm{w}$ & ed any of the fol & blems or concerns? \\
\hline \multicolumn{4}{|l|}{ Check all that apply. } \\
\hline You had no interest in sex & $636(18.8 \%)$ & $181(10.9 \%)$ & $454(26.6 \%)$ \\
\hline You had erection difficulties & - & $268(16.1 \%)$ & - \\
\hline Your vagina felt too dry & - & - & $171(10.0 \%)$ \\
\hline You had pain during or after sex & $185(5.5 \%)$ & $27(1.6 \%)$ & $159(9.2 \%)$ \\
\hline You had difficulty having an orgasm & $247(7.3 \%)$ & $90(5.4 \%)$ & $157(9.2 \%)$ \\
\hline You felt anxious about having sex & $179(5.3 \%)$ & $110(6.6 \%)$ & $69(4.1 \%)$ \\
\hline You did not enjoy sex & $180(5.3 \%)$ & $27(1.6 \%)$ & $153(9.0 \%)$ \\
\hline Some other problem or concern & $146(4.3 \%)$ & $69(4.1 \%)$ & $77(4.5 \%)$ \\
\hline No problems or concerns & $2237(66.3 \%)$ & $1169(70.3 \%)$ & $1068(62.4 \%)$ \\
\hline Missing & $141(4.0 \%)$ & $94(5.3 \%)$ & $47(2.7 \%)$ \\
\hline \multicolumn{4}{|c|}{ Number of sexual problems or concerns (from checklist screener) } \\
\hline No problems or concerns & $2237(66.3 \%)$ & $1169(70.3 \%)$ & $1068(62.4 \%)$ \\
\hline 1 problem or concern & $663(19.6 \%)$ & $308(18.5 \%)$ & $355(20.7 \%)$ \\
\hline 2 problems or concerns & $240(7.1 \%)$ & $121(7.3 \%)$ & $118(6.9 \%)$ \\
\hline 3 problems or concerns & $133(3.9 \%)$ & $44(2.7 \%)$ & $88(5.2 \%)$ \\
\hline 4 or more problems or concerns & $101(3.0 \%)$ & $21(1.2 \%)$ & $81(4.7 \%)$ \\
\hline
\end{tabular}


Table 3 PROMIS SexFS Scores and Differences in Mean Scores for Sexually Active Men and Women Who Did and Did Not Endorse the General and Long List Screeners

\begin{tabular}{|c|c|c|c|c|c|c|}
\hline \multirow[t]{2}{*}{$\begin{array}{l}\text { PROMIS } \\
\text { SexFS domain }\end{array}$} & \multicolumn{2}{|c|}{$\begin{array}{l}\text { PROMIS SexFS Score, } \\
\text { mean (SE) }\end{array}$} & \multirow[t]{2}{*}{$\begin{array}{l}\text { Difference in } \\
\text { means (95 \% CI) }\end{array}$} & \multicolumn{2}{|c|}{$\begin{array}{l}\text { PROMIS SexFS Score, } \\
\text { mean (SE) }\end{array}$} & \multirow{2}{*}{$\begin{array}{l}\text { Difference } \\
\text { in means } \\
(95 \% \mathrm{CI})\end{array}$} \\
\hline & $\begin{array}{l}\text { Endorsed } \\
\text { general } \\
\text { screener }\end{array}$ & $\begin{array}{l}\text { Did not } \\
\text { endorse } \\
\text { general } \\
\text { screener }\end{array}$ & & $\begin{array}{l}\text { Endorsed } \\
\text { long list } \\
\text { screener }\end{array}$ & $\begin{array}{l}\text { Did not } \\
\text { endorse } \\
\text { long list } \\
\text { screener }\end{array}$ & \\
\hline \multicolumn{7}{|l|}{ Women $(n=1178)$} \\
\hline Interest in Sexual Activity & $45.77(0.83)$ & $51.21(0.35)$ & $5.45(3.68,7.21)$ & $46.68(0.72)$ & $51.77(0.36)$ & $5.09(3.52,6.66)$ \\
\hline $\begin{array}{l}\text { Vaginal Lubrication } \\
\text { for Sexual Activity }\end{array}$ & $42.69(1.04)$ & $50.84(0.40)$ & $8.15(5.96,10.35)$ & $43.39(0.93)$ & $51.97(0.37)$ & $8.58(6.63,10.53)$ \\
\hline $\begin{array}{l}\text { Vaginal Discomfort } \\
\text { with Sexual Activity }\end{array}$ & $57.04(1.09)$ & $49.22(0.41)$ & $-7.82(-10.10,-5.54)$ & $56.75(0.85)$ & $48.04(0.39)$ & $-8.71(-10.55,-6.88)$ \\
\hline $\begin{array}{l}\text { Vulvar Discomfort } \\
\text { with Sexual Activity - } \\
\text { Labial }\end{array}$ & $56.03(1.51)$ & $49.25(0.36)$ & $-6.78(-9.83,-3.73)$ & $55.03(1.05)$ & $48.41(0.32)$ & $-6.62(-8.77,-4.46)$ \\
\hline $\begin{array}{l}\text { Vulvar Discomfort } \\
\text { with Sexual Activity- } \\
\text { Clitoral }\end{array}$ & $53.37(1.39)$ & $49.54(0.39)$ & $-3.83(-6.66,-1.00)$ & $53.55(1.10)$ & $48.84(0.34)$ & $-4.71(-6.96,-2.46)$ \\
\hline Orgasm - Ability & $41.78(1.36)$ & $48.61(0.46)$ & $6.83(4.02,9.64)$ & $43.58(1.01)$ & $49.10(0.47)$ & $5.52(3.34,7.70)$ \\
\hline $\begin{array}{l}\text { Satisfaction with } \\
\text { Sex Life }\end{array}$ & $40.33(0.64)$ & $50.20(0.45)$ & $9.86(8.34,11.39)$ & $42.58(0.58)$ & $51.05(0.48)$ & $8.47(6.99,9.95)$ \\
\hline \multicolumn{7}{|l|}{$\operatorname{Men}(n=1423)$} \\
\hline Interest in Sexual Activity & $52.08(0.57)$ & $55.75(0.24)$ & $3.68(2.46,4.89)$ & $51.25(0.57)$ & $55.99(0.23)$ & $4.73(3.52,5.94)$ \\
\hline Erectile Function & $42.22(0.73)$ & $53.61(0.30)$ & $11.40(9.86,12.94)$ & $41.96(0.63)$ & $53.81(0.29)$ & $11.85(10.49,13.21)$ \\
\hline Orgasm - Ability & $46.83(0.80)$ & $53.86(0.27)$ & $7.04(5.38,8.70)$ & $46.70(0.79)$ & $53.96(0.27)$ & $7.26(5.62,8.91)$ \\
\hline $\begin{array}{l}\text { Satisfaction with } \\
\text { Sex Life }\end{array}$ & $43.14(0.65)$ & $52.18(0.34)$ & $9.04(7.61,10.48)$ & $43.72(0.67)$ & $52.17(0.35)$ & $8.45(6.98,9.92)$ \\
\hline
\end{tabular}

( $27 \%$ vs. $16 \%$ ). There were only small differences for interest ( $39 \%$ vs. $33 \%$ ), pain ( $6 \%$ vs. $7 \%$ ), and sexual enjoyment (6\% vs. $4 \%)$.

Third, there were differences in the level of bother associated with problems. Women who answered "yes" to the long list screener (vs. "no") were more bothered by their level of interest (mean score of 4.4 vs. 3.7 on a 5-point scale, $P<0.0001$ ), by pain (3.1 vs. $2.4, P<0.01$ ), and by orgasm (3.3 vs. $2.7, P=0.02$ ). The difference in bother scores for lubrication was smaller and not significant (2.7 vs. 2.5, $P=0.3$ ). Men who answered "yes" to the long list screener (vs. "no") were more bothered by their level of interest (4.0 vs. 3.6, $P=0.04)$ and by erectile difficulties (3.5 vs. 2.8 ,
$P<0.0001)$. The difference in bother scores for orgasm was not significant (3.6 vs. 3.1, $P<0.07$ ). The PROMIS SexFS Bother Regarding Sexual Function domain does not include questions about bother regarding the lack of enjoyment or anxiety concepts.

\section{Construct Validity}

We examined construct validity separately for men and women who were and were not sexually active in the past month. Table 3 presents the PROMIS SexFS scores and differences in mean scores comparing individuals who did and did not endorse the general screener and the long list screener.

Table 4 PROMIS SexFS Scores and Differences in Mean Scores for Sexually Active Men and Women Who Did and Did Not Endorse Problems on Checklist Screener

\begin{tabular}{|c|c|c|c|c|}
\hline \multirow{2}{*}{$\begin{array}{l}\text { Checklist screener } \\
\text { response }\end{array}$} & \multirow{2}{*}{$\begin{array}{l}\text { Corresponding PROMIS SexFS } \\
\text { Domain }\end{array}$} & \multicolumn{2}{|c|}{ PROMIS SexFS Score, mean (SE) } & \multirow{2}{*}{$\begin{array}{l}\text { Difference in means }(95 \% \\
\text { CI) }\end{array}$} \\
\hline & & $\begin{array}{l}\text { Endorsed } \\
\text { problem }\end{array}$ & $\begin{array}{l}\text { Did not endorse } \\
\text { problem }\end{array}$ & \\
\hline \multicolumn{5}{|l|}{ Women $(\mathrm{N}=392)$} \\
\hline No interest & Interest in Sexual Activity & $44.16(0.75)$ & $51.24(0.80)$ & $7.08(4.92,9.23)$ \\
\hline Dryness & Vaginal Lubrication for Sexual Activity & $38.18(0.90)$ & $46.97(0.84)$ & $8.79(6.36,11.22)$ \\
\hline Pain & Vaginal Discomfort with Sexual Activity & $62.96(0.78)$ & $52.25(0.80)$ & $-10.71(-12.90,-8.52)$ \\
\hline Pain & $\begin{array}{l}\text { Vulvar Discomfort with Sexual Activity- } \\
\text { Labial }\end{array}$ & $58.83(1.56)$ & $51.77(0.88)$ & $-7.06(-10.58,-3.53)$ \\
\hline Pain & $\begin{array}{l}\text { Vulvar Discomfort with Sexual Activity- } \\
\text { Clitoral }\end{array}$ & $55.53(1.67)$ & $51.82(0.95)$ & $-3.71(-7.47,0.06)$ \\
\hline Difficulty with orgasm & Orgasm - Ability & $39.12(1.25)$ & $46.93(1.03)$ & $7.81(4.63,10.99)$ \\
\hline No enjoyment & Satisfaction with Sex Life & $39.92(0.79)$ & $44.30(0.68)$ & $4.38(2.33,6.43)$ \\
\hline \multicolumn{5}{|l|}{$\operatorname{Men}(n=375)$} \\
\hline No interest & Interest in Sexual Activity & $46.56(0.82)$ & $54.61(0.44)$ & $8.05(6.24,9.87)$ \\
\hline Erection difficulties & Erectile Function & $39.61(0.60)$ & $48.89(0.80)$ & $9.28(7.31,11.25)$ \\
\hline Difficulty with orgasm & Orgasm - Ability & $42.38(1.33)$ & $48.92(0.71)$ & $6.54(3.59,9.49)$ \\
\hline No enjoyment & Satisfaction with Sex Life & $42.70(2.31)$ & $44.55(0.54)$ & $1.85(-2.81,6.50)$ \\
\hline
\end{tabular}


Table 5 Relationship Between Checklist Endorsement and Reason for Not Having Sexual Activity with a Partner

\begin{tabular}{|c|c|c|c|c|}
\hline \multirow[t]{2}{*}{ Checklist screener response } & \multirow{2}{*}{$\begin{array}{l}\text { Corresponding reason for no } \\
\text { sexual activity with a partner }\end{array}$} & \multicolumn{2}{|l|}{ Reason } & \multirow[t]{2}{*}{$P$ value } \\
\hline & & $\begin{array}{l}\text { Endorsed } \\
\text { problem, \% }\end{array}$ & $\begin{array}{l}\text { Did not endorse } \\
\text { problem, \% }\end{array}$ & \\
\hline \multicolumn{5}{|l|}{ Women $(n=328)$} \\
\hline No interest & Interest in sexual activity & 45.2 & 11.7 & $<0.0001$ \\
\hline Vaginal dryness & Dryness or pain & 26.6 & 3.2 & $<0.0001$ \\
\hline Pain & Dryness or pain & 32.9 & 3.4 & $<0.0001$ \\
\hline Difficulty having orgasm & Difficulties with orgasm & 13.8 & 3.1 & 0.007 \\
\hline No enjoyment & No enjoyment & 32.6 & 5.8 & $<0.0001$ \\
\hline Anxiety & Feeling anxious or stressed & 13.9 & 9.8 & 0.492 \\
\hline \multicolumn{5}{|l|}{ Men $(n=284)$} \\
\hline No interest & No interest & 52.7 & 6.5 & $<0.0001$ \\
\hline Erection difficulties & Erection difficulties & 63.6 & 3.5 & $<0.0001$ \\
\hline Difficulty with orgasm & Difficulties with orgasm & 37.7 & 4.0 & $<0.0001$ \\
\hline No enjoyment & No enjoyment & 8.8 & 3.7 & 0.371 \\
\hline Anxiety & Feeling anxious or stressed & 38.4 & 10.3 & $<0.0001$ \\
\hline
\end{tabular}

* Difference in percentage who endorsed that reason, based on Pearson chi-square test

Sexually active women who said they had a sexual problem on the general or long list screener had lower function on the PROMIS SexFS compared to women who said they did not have a sexual problem (i.e., answered "no" to either screener). The differences were medium to large and statistically significant. Likewise, sexually active men who said they had a sexual problem or concern on the general or long list screener had lower function compared to men who said they did not have a sexual problem or concern (i.e., answered "no" to either screener). The differences were large and statistically significant in all domains.

Table 4 presents the PROMIS SexFS scores and mean differences in scores comparing individuals who did and did not endorse each problem on the checklist screener. Sexually active women who endorsed a specific problem on the checklist screener had decreased function, on average, in the corresponding domain of sexual function on the PROMIS SexFS. All differences were medium or large and statistically significant. Likewise, sexually active men who endorsed a specific problem on the checklist screener had decreased function on average, in the corresponding domain of sexual function as measured by the PROMIS SexFS. All differences were medium or large and statistically significant, with the exception of not enjoying sex, likely due to very small sample size for that response on the checklist screener $(\mathrm{n}=19)$.

\section{Table 6 Recommended Clinical Screener}

\footnotetext{
$\overline{\text { In the past } 12 \text { months, has there ever been a period of } 3 \text { months or more }}$ when you had any of the following problems or concerns? Check all that apply.

You wanted to feel more interest in sexual activity

You had difficulty with erections (penis getting hard or staying hard) MEN ONLY

Your vagina felt too dry - WOMEN ONLY

You had pain during or after sexual activity

You had difficulty having an orgasm

You felt anxious about sexual activity

You did not enjoy sexual activity

Some other sexual problem or concern

No sexual problems or concerns
}

Table 5 shows the relationship between endorsing a problem on the checklist screener and endorsing the same response as a reason for not having sexual activity with a partner in the past 30 days. Among men and women who had not been sexually active in the past 30 days, those who endorsed a specific problem on the checklist screener were more likely to endorse that same reason in response to why they had not had sexual activity with a partner in the past 30 days, with the exception of enjoyment for men (small sample size, as above) and anxiety for women.

\section{DISCUSSION}

In a representative sample of U.S. adults, the prevalence of sexual problems or concerns that were self-reported in an online survey was quite different depending on how the question was asked. When asked as a global yes/no style question, with no recall period and no examples of common sexual problems, 1 in 10 women and 1 in 7 men reported having a sexual problem or concern. When men and women were asked to report specific sexual problems or concerns over the past year, with response options in a checklist style, we found that roughly 1 in 2.5 women and 1 in 3 men reported at least one sexual problem. The discrepancy between the general yes/no screener and the other (long list and checklist) screeners was not unexpected, given the differences in recall period and specificity. However, the discrepancy between the long list and checklist screeners, which were identical in wording but different in format, was striking. The discrepancy appears to be related to the number and type of sexual problems the person had, as well as how bothered he or she was, for many of the domains.

\section{Limitations}

The main limitation of this study is the potential for order effects. The screener questions were administered after the PROMIS SexFS items; participants had already answered 
many questions regarding specific aspects of sexual function by the time they were asked the more general screener questions. Yet the prevalence of reporting a sexual problem on the check list screener, the last one administered to the sample, was within the range found in other national surveys that asked similar questions. The order of administration of the three screeners was not randomized, so it is possible that order magnified or diminished the differences we observed between the items. Because the items within the individual PROMIS SexFS domains were randomized, we were able to test for order effects between items in that context. We tested item pairs in the domains of interest, erectile function, and vaginal discomfort, and found no evidence of order effects (effect sizes $0.002-0.09, P>0.51)$.

\section{Recommendation}

All of the screeners tested showed evidence for basic validity and had minimal missing data, but they varied substantially in the number of people who endorsed them. A major consideration in determining which screener to recommend for routine use in clinical practice is the extent to which responses to the screener help guide the patient's clinical care. Using this rationale, the checklist screener is the best choice. It was endorsed by a greater number of participants compared to other ways of asking the question, and thus could facilitate patient-provider communication about sexual problems for a larger group of people. For instance, providers might be more likely to raise the issue with their patients if they are aware of patients' concerns prior to the visit. Moreover, the checklist screener format allows for efficient identification of specific problems over time and can help to guide the selection of specific interventions. Finally, in the context of identifying and treating patients with sexual concerns, the hazard of overidentifying patients who report concerns on the screener but are not bothered by them or do not prioritize them is small compared to that of missing patients with true problems, further supporting the more specific checklist approach.

Nevertheless, in the context of an existing "review of systems" style intake form, where the inclusion of the checklist screener would prove overly burdensome or infeasible for other reasons, we recommend that the general screener, or specifically the phrase "sexual problems or concerns," be included as an available field for both men and women. While this screener does not have the specificity to identify particular sexual problems that could inform treatment options, it does identify which patients might benefit from further discussion with the provider, and is therefore preferable to omitting the item entirely.

After analyses, we tested modifications to the wording of the checklist screener in a second round of cognitive interviews. Based on the results, we 1) changed "no interest in sexual activity" to "wanted to feel more interest in sexual activity" in order to incorporate a sense of bother to the response, and 2) clarified the meaning of "erection difficulties." The final recommended screener is displayed in Table 6.

\section{CONCLUSIONS}

We developed and validated a single-item screener to capture common sexual concerns that men and women had experienced over the past year. Our understanding of the sexual side effects of medical treatments would be improved if this screener were routinely used and analyzed. Adoption of this item across clinical sites would also facilitate multi-site research efforts to improve sexual outcomes for patients.

\section{Acknowledgments:}

Financial disclosures: none reported.

Funding/Support: The study was supported by funding from the National Institute of Arthritis and Musculoskeletal and Skin Diseases (U01AR052186). Dr. Flynn was funded in part by the Research and Education Program Fund, a component of the Advancing a Healthier Wisconsin endowment at the Medical College of Wisconsin. Dr. Lindau's contribution was funded in part by a career development award from the National Institute on Aging (K23AG032870).

Disclaimer: The contents of this manuscript are solely the responsibility of the authors and do not necessarily represent the official views of the National Institutes of Health, the National Institute on Aging, or the National Institute of Arthritis and Musculoskeletal Skin Diseases.

Additional Contributions: We wish to acknowledge the contributions and support of the members of the PROMIS Sexual Function domain group and the Scientific Network on Female Sexual Health and Cancer.

Conflict of interest: The authors declare that they do not have a conflict of interest.

Corresponding Author: Kathryn E. Flynn, PhD; Center for Patient Care and Outcomes Research, Department of Medicine, Medical College of Wisconsin, Milwaukee, WI 53226, USA (e-mail: kflynn@mcw.edu).

\section{REFERENCES}

1. Laumann EO, Paik A, Rosen RC. Sexual dysfunction in the United States: prevalence and predictors. JAMA. 1999;281:537-44.

2. Lindau ST, Schumm LP, Laumann EO, Levinson W, O'Muircheartaigh CA, Waite LJ. A study of sexuality and health among older adults in the United States. N Engl J Med. 2007;357:762-74.

3. Gott M, Galena E, Hinchliff S, Elford H. "Opening a can of worms": GP and practice nurse barriers to talking about sexual health in primary care. Fam Pract. 2004;21:528-36.

4. Gott M, Hinchliff $\mathbf{S}$, Galena E. General practitioner attitudes to discussing sexual health issues with older people. Soc Sci Med. 2004;58:2093-103.

5. Sobecki JN, Curlin FA, Rasinski KA, Lindau ST. What we don't talk about when we don't talk about sex: results of a national survey of U.S. obstetrician/gynecologists. J Sex Med. 2012;9:1285-94.

6. Lindau ST, Abramsohn E, Gosch K, et al. Patterns and loss of sexual activity in the year following hospitalization for acute myocardial infarction (a United States National Multisite Observational Study). Am J Cardiol. 2012;109: 1439-44.

7. Flynn KE, Reese JB, Jeffery DD, et al. Patient experiences with communication about sex during and after treatment for cancer. Psychooncology. 2012;21:594-601.

8. Lindau ST, Surawska H, Paice J, Baron SR. Communication about sexuality and intimacy in couples affected by lung cancer and their clinical-care providers. Psychooncology. 2011;20:179-85.

9. Abramsohn EM, Decker C, Garavalia B, et al. I'm not just a heart, I'm a whole person here": a qualitative study to improve sexual outcomes in women with myocardial infarction. J Am Heart Assoc. 2013;2(4):e000199.

10. Hordern AJ, Street AF. Communicating about patient sexuality and intimacy after cancer: mismatched expectations and unmet needs. Med J Aust. 2007; 186:224-7. 
11. Stead ML, Brown JM, Fallowfield L, Selby P. Lack of communication between healthcare professionals and women with ovarian cancer about sexual issues. Br J Cancer. 2003;88:666-71.

12. Hartmann U, Burkart M. Erectile dysfunctions in patient-physician communication: optimized strategies for addressing sexual issues and the benefit of using a patient questionnaire. J Sex Med. 2007;4:38-46.

13. Rosen RC, Riley A, Wagner G, Osterloh IH, Kirkpatrick J, Mishra A. The international index of erectile function (IIEF): a multidimensional scale for assessment of erectile dysfunction. Urology. 1997;49:822-30.

14. Rosen R, Brown C, Heiman J, et al. The Female Sexual Function Index (FSFI): a multidimensional self-report instrument for the assessment of female sexual function. J Sex Marital Ther. 2000;26:191-208.

15. Fuchs M. Gender-of-interviewer effects in a video-enhanced web survey: Results from a randomized field experiment. Social Psychology. 2009;40:37-42.

16. Alexander AM, Flynn KE, Hahn EA, et al. Improving patients' understanding of terms and phrases commonly used in self-reported measures of sexual function. J Sex Med. 2014;11:1991-8.
17. Knowledge Networks. KnowledgePanel Design Summary. Available at: http://www.knowledgenetworks.com/knpanel/KNPanel-Design-Summary.html. Accessed September 8, 2014.

18. Flynn KE, Jeffery DD, Keefe FJ, et al. Sexual functioning along the cancer continuum: focus group results from the Patient-Reported Outcomes Measurement Information System (PROMIS®). Psychooncology. 2011;20:378-86.

19. Flynn KE, Lin L, Cyranowski JM, et al. Development of the $\mathrm{NIH}$ PROMIS ${ }^{\circ}$ Sexual Function and Satisfaction Measures in patients with cancer. J Sex Med. 2013;10(Suppl 1):43-52.

20. Fortune-Greeley AK, Flynn KE, Jeffery DD, et al. Using cognitive interviews to evaluate items for measuring sexual functioning across cancer populations: improvements and remaining challenges. Qual Life Res. 2009; 18:1085-93.

21. Flynn K. Conceptual Model for the PROMIS Sexual Function and Satisfaction Measure. Paper presented at: International Society for Quality of Life Research 20th Annual Conference 2013.

22. Cohen J. Statistical Power Analysis for the Behavioral Sciences. 2nd ed. Hillsdale, New Jersey: Lawrence Erlbaum Associates; 1988. 